\title{
OTOMOTIV KULLANICILARINDA GÖRÜNTÜLEME YÖNTEMİ KULLANILARAK KONFOR AÇILARININ ARAŞTIRILMASI
}

\author{
Onur ÜLKER ${ }^{1 *}$, Mehmet Ali ALTIN², Mercan Haddad DERAFSHI ${ }^{3}$ \\ ${ }^{1}$ Eskişehir Teknik Üniversitesi, Mimarlık ve Tasarım Fakültesi, İç Mimarlık Bölümü \\ ORCID No: https://orcid.org/ 0000-0002-8108-6269 \\ 2 Eskişehir Teknik Üniversitesi, Mimarlık ve Tasarım Fakültesi, İç Mimarlık Bölümü Eskişehir \\ ORCID No: https://orcid.org/0000-0001-8992-7088 \\ 3 University of Tennessee at Martin, Department of Family and Consumer Sciences College of Agriculture \\ ORCID No: https://orcid.org/0000-0001-8887-2185
}

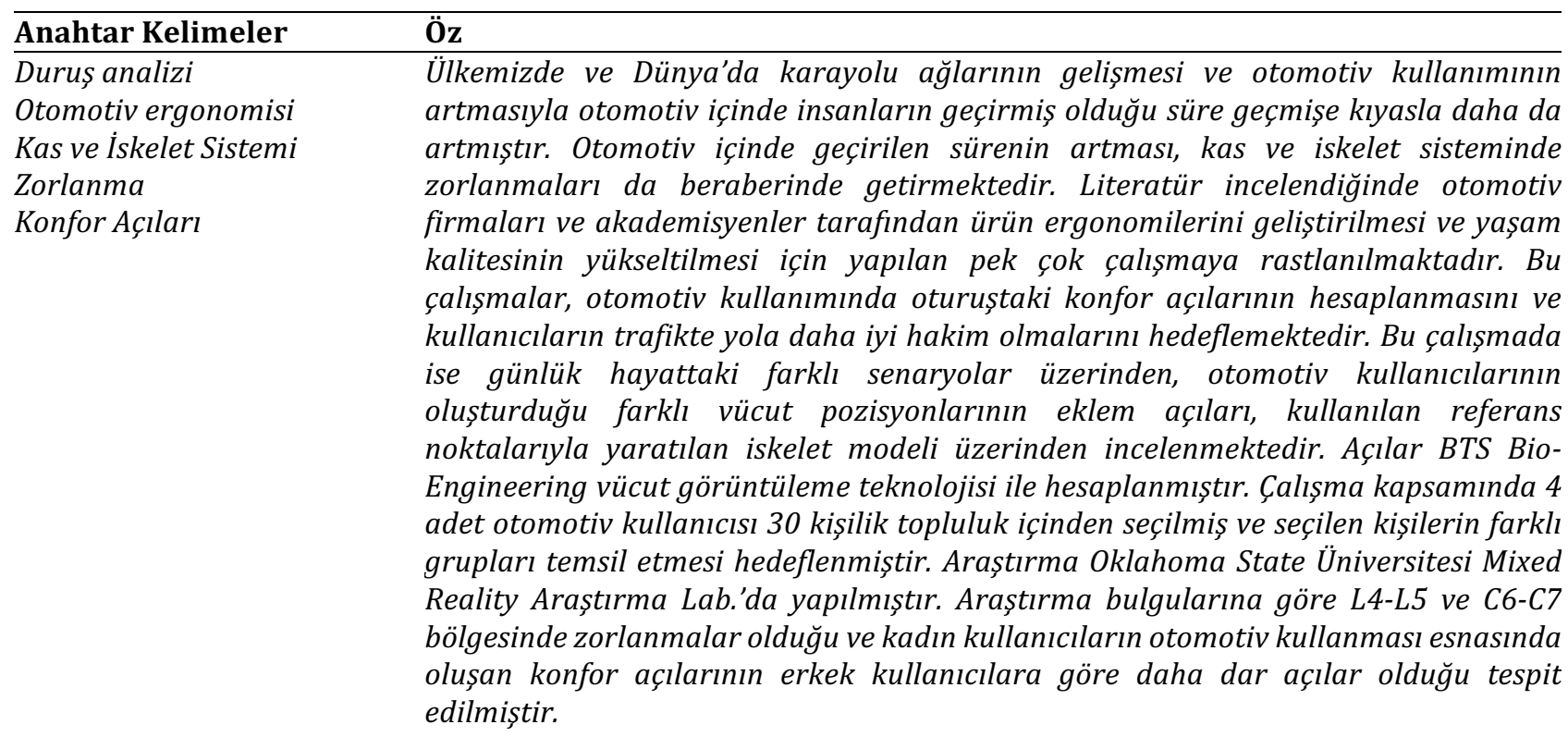

\section{INVESTIGATION OF COMFORT ANGLES BY USING} THE IMAGING METHOD

\begin{tabular}{ll}
\hline Keywords & Abstract \\
\hline Posture analysis & With the development of highway networks and the increase in automotive use in our \\
Car Ergonomics & country and in the world, the time spent in automotive vehicles has increased \\
Musculoskeletal System & compared to the past. Prolonged driving causes difficulties in the musculoskeletal \\
Stress & astem. Extensive literature conducted by automotive companies and academicians, \\
Comfort angles & assessed comfort angles in automotive use and addressed driver comfort in high traffic. \\
& In our study, different body angles were examined by creating a skeleton model. This \\
model represents automotive users who drive on a daily basis. Angles were calculated \\
by BTS Bio-Engineering software. Four participants were chosen from a group of 30 \\
drivers to represent diverse daily drivers. The study was conducted at the Mix Reality \\
Lab of Oklahoma State University. Research findings indicate that there are strains in \\
the lumbar spine (L4-L5), cervical spine (C6-C7), and that the comfort angles offemale \\
drivers are narrower than their male counterparts.
\end{tabular}

\begin{abstract}
Araştırma Makalesi
\end{abstract}
Başvuru Tarihi

Kabul Tarihi

\author{
Research Article \\ Submission Date \\ Accepted Date
}

\footnotetext{
*Sorumlu yazar e-posta: onurulker@eskisehir.edu.tr
} 


\section{Giriş}

Ergonomi bilimi insan-mekan ve insan-makine ilişkisinin en konforlu biçimde oluşturulmasını hedefler. Ergonomi biliminin temel amacı, insan makine ara kesitinde, insanları makinelere göre pozisyon almaktansa, makine tasarımının uygun hale getirilmesini sağlamaktır (Carayon and Smith 2000; Ulker, 2020).

Ergonomi bilimi imalat esnasında verilen işlerin çalışana göre planlanmasını hedefler böylelikle çalışanlarda oluşabilecek zorlanma ve stresin en az seviyeye indirilmesini sağlar. İşveren ve işçi sağlık harcamalarının da azalmasını sağlayarak ülke ekonomisine katkıda bulunur.

Otomotiv sektörü ile ilişkili iç mekan konfor çalışmalarının pek çoğu son atmış yılda yapılmıştır. $\mathrm{Bu}$ çalışmada ve literatürdeki araştırmalarda otomotiv kullanıcılarının kas ve iskelet sisteminde deformasyon ve zorlanmalar ile ilişkili sorunlara ve çözüm önerilerine değinilmiştir. Son yirmi yılda yapılan araştırmaların ise; otomotiv iç mekan tasarımı ve otomotiv koltukları ile ilişkili olduğu gözlemlenmektedir. İnsan anatomisine uygun olmayan koltuk tasarımları nedeniyle, uzun mesafe sürüşlerinde kas, iskelet ve endokrin sisteminde hasar oluştuğu gözlemlenmiştir (Zhang vd., 2000; Kaya ve Akalp, 2017; Straker ve Mekhora, 2000, Gowtham vd., 2020)

Bu çalışmada, daha önce yapılmış araștırmalardan farklı olarak, uzun süreli ve kısa süreli otomotiv kullanan kadın ve erkek sürücülerde konfor açılarının ve vücut duruşlarının dijital kameralar yardımı ile tespiti hedeflenmiştir.

Otomotiv kullanıcılarının duruşlarını incelemek için kızıl ötesi kameralar kullanılarak bilgisayar destekli görüntü yakalama analizi yapılmıştır.

Daha önce yapılmış olan çalışmalar incelendiğinde, görüntüleme tekniği kullanılarak otomotiv kullanıcılarının konfor açılarının araştırıldığı çalışmalarla karşılaşılmış ama cinsiyet ve yaş farkına göre ve farklı senaryolara göre araç içi duruşlarının incelendiği bir çalışma olmadığı gözlemlenmiştir. Literatüre katkı sağlamak amacıyla, farklı duruşlardaki konfor açıları araştırılmıştır.

Literatür incelendiğinde, araç iç mekan tasarımdaki en önemli 3 noktadan birisi olan koltuk tasarımı pek çok araştırmacının ilgisini çekmiştir (Zhang vd., 1996; Guenaelle 1995; Kamp 2002; Schmidt vd., 2014).

Otomotiv firmaları ve bağımsız araştırmacılar, konfor açılarına dayalı ergonomik oturma postürünü araştırmış ve belirli aralıkta konfor açıları önerilmiştir. Bu çalışmada da görüntüleme tekniği kullanılarak optimum açların bulunması hedeflenmiștir.

\section{Bilimsel Yazın Taraması}

Günümüzde, ticari kaygllar duyan otomotiv imalat firmaları, tasarladıkları araçlarda iç mekan tasarımlarını standart ölçüye sahip insan formuna göre planlamaktadır. Otomobillere ölçüsü ayarlanabilen koltuk, direksiyon gibi donanımlar yerleștirilmiş olsa bile, firmaların oluşturmuș olduğu bu aralık seviyeleri dünya üzerindeki bütün toplumlara hitap etmemektedir. İnsan ölçüleri farklı coğrafyalarda yaşayan toplumlara ve irklara göre farklılıklar göstermektedir. Alman ve Japon toplumunu örnek olarak gösterecek olursak, vücut ölçülerindeki ortalama farkı $30 \mathrm{~cm}$ gibi önemli büyüktedir (Eldem vd., 2019).

Otomotiv iç mekan tasarımı yapılırken, güvenli sürüş ve kullanıcı konforu öne çıkar. Doğru ölçülerde imal edilmemiş otomotivler kazaya neden olabilir. Sürücü koltuklarının yükseklik ayarları doğru olmalı, direksiyon simidi kullanıcıların dizine değmemeli, otomotiv kullanımı esnasında kullanıcıların göz mesafesi yolu tamamen tarayacak yükseklikte olmalıdır. Gaz, fren ve debriyaj pedallarının mesafesi iyi ayarlanmalı ve kullanıcıların antropometrik değerlerine uygun olmalıdır (Kaya ve Özok, 2017).

Otomotiv sektöründe çalışan firmalar, araç iç mekan ergonomisinin gelişimi ve sürüş konforunun artması için koltuk tasarımı ve araç kullanımı esnasındaki vücut duruşlarının araştırılmasına önem vermektedir (Gyi vd 1998; Guenaelle 1995; Andreoni vd., 1999). Otomotiv kullanımı esansında ve otomotiv tasarımındaki en önemli unsur kullanıcıların ve yolcuların vücut duruşudur (Gyi vd., 1998).

Araç iç konforu ve güvenliği ergonomik risk faktörlerine bağlıdır (Zhang vd., 1996). Otomotivler için iyi bir koltuk tasarlanmadığı durumda, bel ağrısı, sırt ağrısı ve boyun ağrısı kronikleşebilir ve kas iskelet sisteminde kalıcı problemlere yol açabilir (Grieco, 1998). Otomotiv koltuk tasarımı, konutlarda kullanılan koltuklara kıyasla daha kompleks ve zor kriterlere bağlıdır. Konutlarda kullanılan koltukla otomotivde kullanılan koltukların arasındaki en önemli fark ayakların pedallara basması gerekliliğidir. Araç kullanılırken sürekli gaz, debriyaj ve fren pedallarının kullanılmasından dolayı bel ve sırt kısmının mutlaka destekli olması gerekmektedir. Bel ve sırt kısımlarında yeterli destek olmadığ durumda vücut dengesi kaybolmakta sağ veya sol bölgelere fazla yük binmektedir.

Yük dağılımını dengelemek amacıyla koltuk tasarımında çeşitli eklentiler yapılmakta, koltuklara yapılan bu eklentiler sürücünün hareketlerini de kısıtlamaktadır. Hareketleri kısıtlanan sürücülerin belirli bir süre sonra sürüş güvenliği tehlikeye düşer. Otomotiv koltukları tasarlanırken sadece kullanıcıların nasıl rahat edeceği değil aynı zamanda kullanıcıların trafik içerisindeki görüș alanı ve araç 
içindeki kumanda yeteneğinin de kaybolmaması amaçlanmalıdır. (Chaffin ve Anderson 1991).

Araç kullanırken, lumbar bölgesinde deformasyonlar ve vücudun boyun ve sırt bölgelerinde ağrılar oluşmaktadır. Uzun yolculuklar sonunda sürekli gaz pedalına basmaktan bacak kaslarında kramplar ve kan dolaşımında bozulmalar yaşanmaktadır. Büyük şehirlerde dur-kalk yaparak ilerlenmesi durumunda omurilik disklerinde dejenerasyon oluşmaktadır. (Huang vd., 2004)

Literatür incelendiğinde, otomotiv sektöründe faaliyet gösteren Ar-Ge birimleri ve bağımsız araştırmacıların yaptığı 30'dan fazla yayınlanmış çalışmaya ulaşılmıştır. Çalışmaların pek çoğunda, sağlıklı vücut duruşunun araştırılmasında en doğru çalışma yönteminin eklemlerdeki açıların incelenmesi olduğu belirtilmiştir. Araç içi oturma duruşlarına dair ilk çalışma, 1940 yılında Lay ve Fisher tarafından yapılmıştır. Lay ve Fisher, çalışmasında 250 kişinin katılımıyla, kalça eklem açısının 104-107 derece arasında olması gerektiğini belirtmiştir. Konu hakkında en çarpıcı çalışma ise 1979 yılında Babbs tarafından yapılmış, bütün eklemlerin açılarının hesaplamaları ve ölçümleri yapılmıştır. Bu çalışma DIN 33408 standardına (1987) işı tutmuş ve optimum açılar standartlaşmıştır. Son yllarda ise dijital modelleme ile RAMSIS (1994) yazılımı oluşturulmuş, bilgisayar ortamında optimum açılar hesaplanmıştır (Lay ve Fisher 1940; DIN 33408; Seidl, 1997).

Graf vd., 1995 yılında, beş farklı günlük oturma eylemini incelemiş ve vücut duruşları hakkında araștırma yapmışlardır. Vücut duruşumuzun sağlıklı olması için eklemlerimiz vücudumuzun her hareketinde doğru pozisyonu alması gereklidir. Vücudumuz kas aktivitesi sırasında ligamentlerin (bağ) desteği ile stabil kalmak için, birçok kasın uyumlu çalışmasını sağlar. (Graf vd., 1995).

Andreoni vd., 2002 yılında otomotiv kullanımındaki vücut duruşlarının araştırılması ve kullanılan otomotiv koltuklarının üzerindeki basınç değerlerini ölçmek için metot analizi yapmışlardır. Araştırma kapsamında kullanılan görüntüleme yönteminde vücut üzerindeki 21 noktaya ve koltuk üzerinde 7 noktaya fosforlu işaretleyici toplar yerleştirilmiş, vücut üzerinde 14 farklı bölgenin açısı hesaplanmıştır. Leğen kemiği bölgesinin \%66, Lumbar bölgesinin \%27 ve sırt bölgesinin \%7 basınç uyguladığı iddia edilmiştir (Andreoni vd.,1999).

Zhou vd., 2017 yılında otomotiv kullanıcılarının rahatsız oldukları vücut açılarını araştırmışlardır. 2 farklı araç kokpit numunesini oluşturmuşlar, bu numunelerde, direksiyon açısı, koltuk açısı, pedalların yerleşimi ve açıları incelenmiş, ideal kullanım koşullarını önermişlerdir (Zhou vd., 2017). olan araç koltuğu tasarımı üzerinde çalışmalar yapmıştır. Çalışmalar BMW firmasıyla birlikte yürütülmüş, 21 katılımcı ile çalışılmış ve 3 farklı koltuk modeli tasarlanmıştır. Kullanıcıların otomotiv koltuğundan, rahatlık, şıklık, sportiflik ve kaza esnasında koruyucu olmasını beklediklerini ifade etmişlerdir (Kamp, 2012).

Vogt vd., 2005 yılında yaptıkları çalışmada, RAMSIS (Rechergestütztes Anthropometrisches Menschmodell zur Insassen-Simulation) yazılımının gelişim sürecini ve optimum açı değerlerini açıklamışlardır. RAMSIS yazılımı, Alman Ergonomi Enstitüsü ve Münih Teknik Üniversitesi tarafından geliștirilmiştir. RAMSIS yazılımının hedefi ergonomik araç iç tasarımı yapmaktır (Vogt vd., 2005). RAMSIS yazılımı hazırlanırken, insan- araç birleșiminde en önemli unsur olan konfor açıları ele alınmıştır. RAMSIS yazılımına ait kullanıcı arayüzü Şekil 1'de verilmiştir.

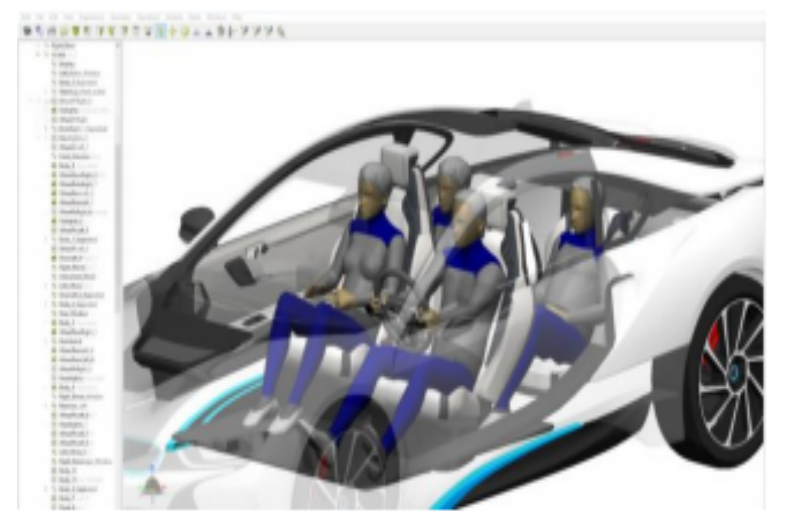

Şekil 1. RAMSIS Yazılımı Kullanıcı Arayüz Görüntüsü (Kuebler vd., 2018)

Schmidt vd., 2014 yılında otomotiv kullanıcılarının, konfor açılarının yer aldığı 30 adet makaleyi incelemiş ve derleme yapmışlardır. Yapılan derlemede çalışmaları ele alan bir tablo hazırlanmış ve 14 konfor açısı üzerinde durulmuştur (Schmidt vd., 2014).

Daha önce yapılmış olan akademik çalışmalarda RULA (Rapid Upper Limb Assessment), RAMSIS (Rechergestütztes Anthropometrisches Menschmodell zur Insassen-Simulation), OWAS (Ovako Working Postures Analysing System), CATIA V5 araştırma yöntemleri ve yazılımları kullanılarak kas iskelet sistemi incelenmiștir (Brisson vd., 1999). $\mathrm{Bu}$ çalışmada ise BTS Bio-Engineering Motion Capture görüntü yakalama tekniği kullanılarak sayısal değerler elde edilmiştir. 


\section{Yöntem}

Araștırmamız, 22-06-2018 ile 22-06-2019 tarihleri arasında, Oklahoma State Üniversitesi 19-171 sayı ve numaralı etik kurul kararına bağlı kalınarak, Stillwater kentinde bulunan Oklahoma State Üniversitesi kampüsünde yapılmıştır.

Oklahoma eyaletinde yaşayan, 30 kişilik Türk grubu içerisinden, 4 kişi rastgele seçim yöntemi ile seçilmiştir. Seçilen kişilerin boy ortalaması erkekler için, $175 \mathrm{~cm}$, kadınlar için $162 \mathrm{~cm}$, kilo ortalaması erkekler için $78 \mathrm{~kg}$, kadınlar için, $59 \mathrm{~kg}$. olarak ölçülmüştür.

Araştırmaya katılanların vücutlarında 14 farklı noktaya eklem hareketlerini ve açllarını tespit etmek için fosforlu işaretleyici küreler yapıştırılmıştır. Şekil 1. Fosforlu işaretleyici kürelerin yapıştırıldığı yerler gösterilmiştir. Şekil 2'de katılımcıların vücutlarına yapıştırılan işaretleyici kürelerin yerleri verilmiştir.

Eğitim ve İnsan Bilimleri Fakültesinde yer alan Mixed Reality laboratuvarına otomotiv simülasyonu yapmak için düzenek kurulmuştur. Kurulan düzenekte, otomatik vites kullanımı modellenmiștir. Düzenek hazırlı̆̆ı, ikinci el Ford marka bir araca ait koltuk vites ve fren-gaz takımları sökülerek ve laboratuvarda kutu profiller kullanılarak gerçek koşulları aratmayacak şekilde yapılmıștır.

Son yıllarda otomatik vitesli araçların satış rakamları yüksek olduğu için otomatik vites düzeneği tercih edilmiştir. Araştırmamızda manuel vites takımı ile çalışan bir otomotiv tercih edilmiş olsaydı sonuçlarda farklılık olabilirdi.

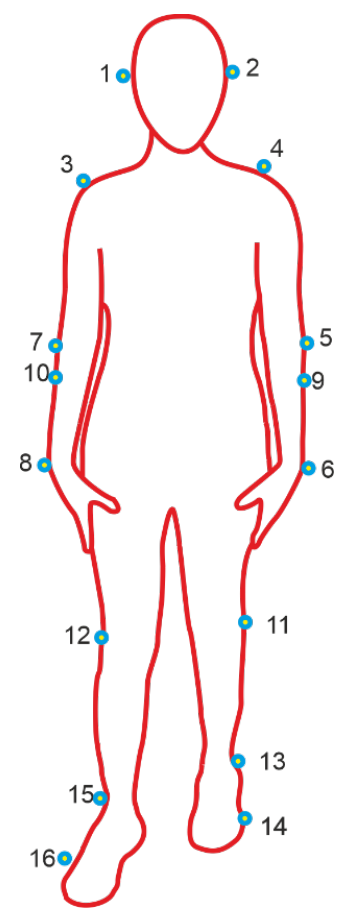

Şekil 2. Vücutta İșaretleyici Kürelerin Yapıștırıldığı Bölgeler
Deneye katılanların otomotiv sürüş esnasında aldıkları pozisyonlar modellenmiştir. Sürüş esnasında oluşabilecek pozisyonlar BTS BioEngineering yazılımı ve kamera sistemi kullanılarak görselleştirilmiştir. Çalışma yapılan "Mixed Reality" laboratuvarı ve kızlötesi kamera düzeneğine ait görsel Şekil 3'te verilmiștir.

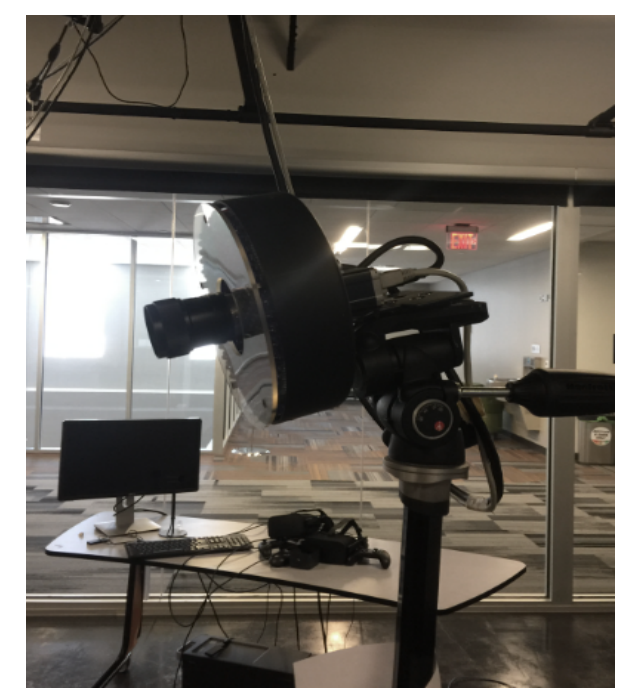

\section{Şekil 3. Mixed Reality Lab. BTS Bio-Engineering Dijital Kamera Sistemi}

Araştırma kapsamında kullanılmış olan, BTS BioEngineering Motion Capture yazilım ve donanımının teknik özellikleri incelendiğinde, çözünürlüğü 1 mega piksel ve en yüksek frekans yakalama miktarı 300 fps olan yedi adet kızılötesi dijital kamera bulunduğu görülmektedir.

Konfor açlları kamera yardımı ile kayıt altına alınmıştır. Konfor açılarına ait hesaplamalara ait denklemler aşağıda verilmiştir (1-7).

$\theta(t)=\left[\begin{array}{lllllll}\theta_{\boldsymbol{I}}(t) & \ldots & \ldots & \ldots & \theta_{j}(t) \ldots \ldots . & \left.\theta_{\boldsymbol{J}}(t)\right]^{\mathrm{T}},\end{array}\right.$

$\theta j^{*}(\theta j=1, \ldots \ldots . . . J)$, bağımsız $j$ vücut açı noktalarını ve $t$ $[0, T]$ ise zaman aralığını temsil etmektedir. Burada amaç, bağımsız hareketlerin nicel şekilde ölçülmesi ve hareketlerin görev alanlarındaki gruplara göre sınıflandırılmasıdır.

$$
\begin{aligned}
& C_{x}^{i}=\int_{0}^{T}\left(x(t)-x^{i}(t)\right) d t, \\
& C_{y}^{i}=\int_{0}^{T}\left(y(t)-y^{i}(t)\right) d t, \\
& C_{z}^{i}=\int_{0}^{T}\left(z(t)-z^{i}(t)\right) d t,
\end{aligned}
$$

Burada, $[x(t) y(t) z(t)]^{\mathrm{T}}$ ve $\left[\begin{array}{lll}x^{i}(t) & y^{i}(t) & z^{i}(t)\end{array}\right]^{\mathrm{T}}$ etki yörüngesini ifade etmektedir. $C_{x}^{i}, C_{y}^{i}$ ve $C_{z}^{i}$ eklem 
hareketindeki bağımlı yörünge dengeleyicileridir. Farklı eklem rotasyonlarındaki etkilerinin 100 'lük sistemde karşılaştırılması için 5-6 ve 7 denklemleri kullanılır (Park vd., 2005).

$$
\begin{aligned}
& P C_{x}^{i}=100 \frac{C_{x}^{i}}{\sum_{j=1}^{J}\left|C_{x}^{j}\right|}, \\
& P C_{y}^{i}=100 \frac{C_{y}^{i}}{\sum_{j=1}^{J}\left|C_{y}^{j}\right|}, \\
& P C_{z}^{i}=100 \frac{C_{z}^{i}}{\sum_{j=1}^{J}\left|C_{z}^{j}\right|} .
\end{aligned}
$$

1-Numaralı sürüş simülasyonu

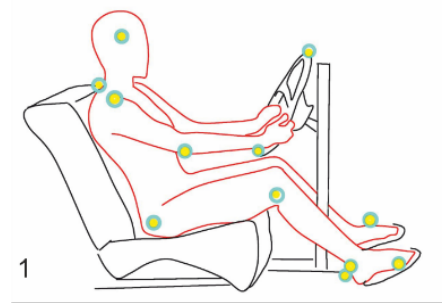

2-Numaralı sürüş simülasyonu

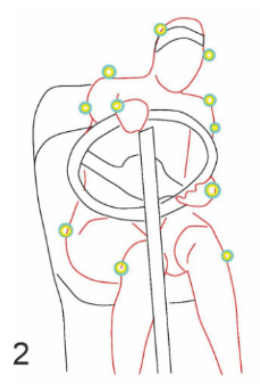

3-Numaralı sürüş simülasyonu

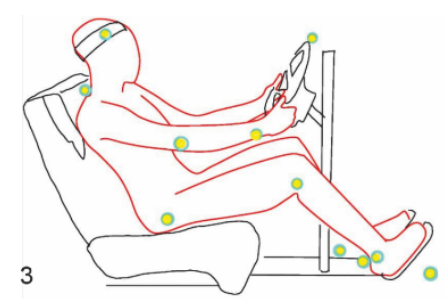

4-Numaralı sürüș simülasyonu

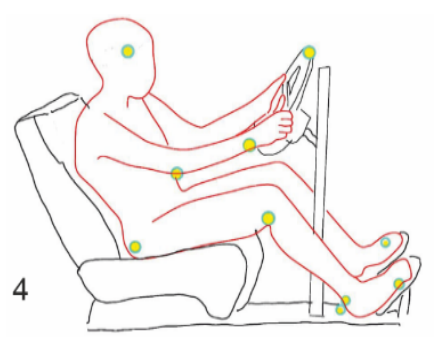

Şekil 4. Farklı Sürüş Duruşlarına Ait Görseller

Şekil 4' de görüntüleme yöntemi kullanılarak yapılmış farklı simülasyonlara ait duruşların görselleri verilmiştir. Otomotiv kullanımı esnasında sıklıkla oluşan hareketler,

1. Şerit değiştirmeden yolu takip etmek,

2. Sola doğru viraj alma pozisyonu,

3. Sağa doğru viraj alma pozisyonu,

4. Aniden șerit değiștirme durumu,

Otomotiv kullanımdaki konfor açıları, DIN 334081:2008-3 standardına bağlı kalarak oluşturulmuştur. DIN 33408 standardına ait görsel Şekil 5'te paylaşılmıştır.

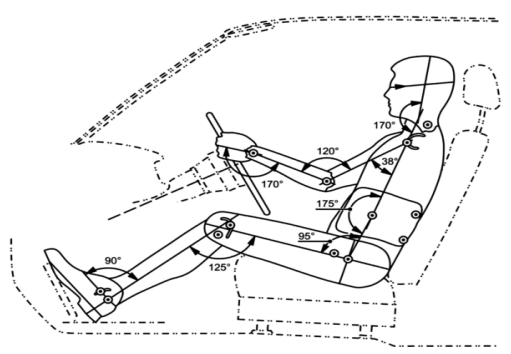

Şekil 5. DIN 33408'e konfor açıları (DIN 33408)

Otomotiv kullanıcılarının:

- Dirsek eklemi açısı,

- Omuz eklemi açısı,

- Kalça eklem açısı,

- Diz eklem açısı,

- Ayak Bileği Eklem Açısı,

İncelenmiştir ve sayısallaştırılmıştır. Ölçüm yapılan konfor açllarına ait görsel Şekil 6’da verilmiştir.

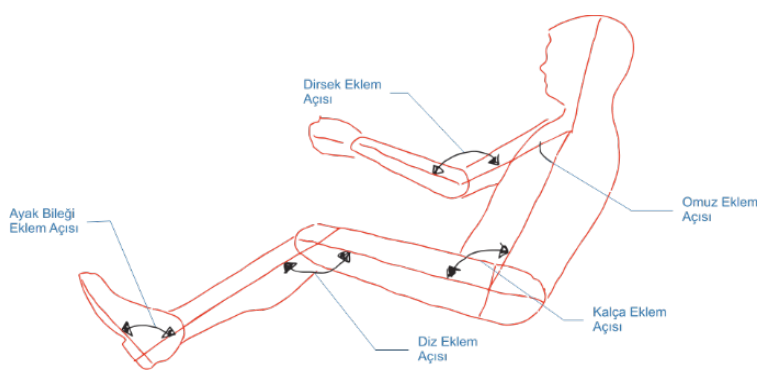

Şekil 6. Ölçüm Yapılan Konfor Açıları 


\section{Sonuçlar}

Araştırmamıza gönüllü katılan dört kişiden, ikisi kadın, ikisi erkektir. Böylelikle erkek ve kadınların otomotiv içerisindeki olası farklı duruşları analiz edilmiştir. Katılımcıların ayak bileği açısı, diz eklem açısı, kalça eklem açısı, omuz eklem açısı, dirsek eklem açlları incelenmiştir. Ölçüm yapılan konfor açıları Şekil 7'de verilmiştir.

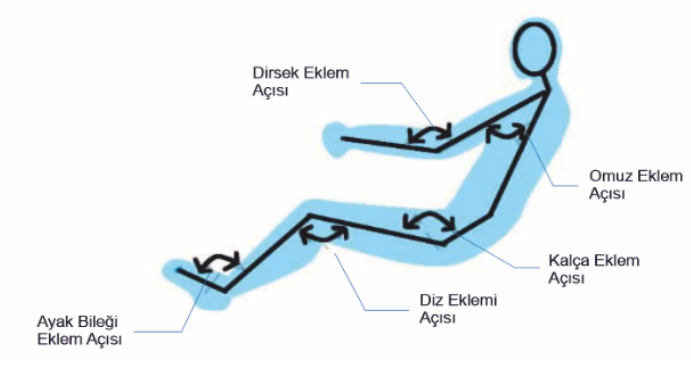

Otomotiv kullanırken oluşan vücut duruşunda sağ profilden ölçüm yapılan açılar

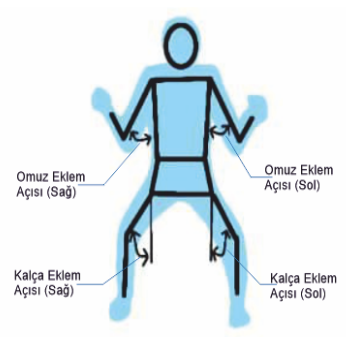

$50 \mathrm{~km}$ mesafeden daha az otomotiv Kullanılması hali

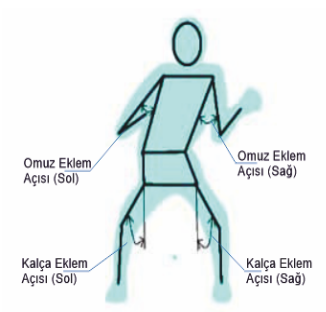

Sağa keskin dönüş yapılması hali

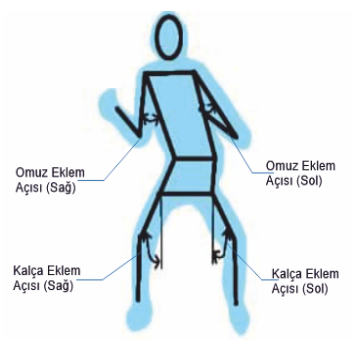

Sola keskin dönüş yapılması hali

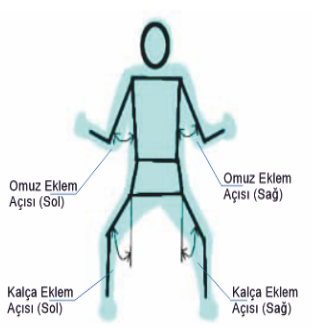

$50 \mathrm{~km}$ mesafen daha fazla otomotiv kullanılması hali

\section{Şekil 7. Hesaplanan Konfor Açıları}

SPSS paket programı kullanılarak, BTS BioEngineering yazılımı ile elde edilen verilerin normal dağılıma sahip olup olmadığına bakılmıș, verilerin Kolmogorov Simirnov ve Shapiro Wilk testlerinin sonuçlarına bakılmış, çarpıklık ve basıklık değerleri incelenmiş ayrıca varyasyon katsayısı \%16 çıkmıştır, bu değerlere göre konfor açllarının normal dağılıma sahip olduğu tespit edilmiştir.
Konfor açıları, kullanım şekline ve kullanıcıların verilerine bağlı kalınarak çift yönlü varyans analizi yapılmıştır.

Tespit edilen değerlerin gruplandırılması amacıyla Duncan çoklu aralık testi tercih yapılmıştır. Araç kullanımı esnasındaki vücut açılarının tespitinin ve analizinin yapılması için hesaplanan açılar, katılımcılar (yaş cinsiyet), sürüş modu ve sürüș duruş türleri ile ilişkili olarak tekli veya grup etkileşimi vücut açları üzerindeki etkisinine ait varyans analizi Tablo 4'te verilmiştir.

Tablo 4. Varyans Analiz Tablosu

\begin{tabular}{|c|c|c|c|c|c|}
\hline Değișkenler & $\begin{array}{c}\text { Karelerin } \\
\text { Toplamı }\end{array}$ & $\begin{array}{c}\text { Serbestlik } \\
\text { Derecesi } \\
\end{array}$ & $\begin{array}{c}\text { Karelerin } \\
\text { Ortalaması } \\
\end{array}$ & $\mathrm{F}$ & $\begin{array}{c}\text { Hata } \\
\text { Seviyesi }\end{array}$ \\
\hline $\begin{array}{l}\text { Eklem } \\
\text { bölgeleri }\end{array}$ & 1923371,05 & 13 & $\begin{array}{l}147951,62 \\
2\end{array}$ & $\begin{array}{l}69697,5 \\
04\end{array}$ & 0,00 \\
\hline $\begin{array}{l}\text { Sürüş } \\
\text { koşulları }\end{array}$ & 1574,647 & 3 & 524,882 & 247,263 & ,000 \\
\hline $\begin{array}{l}\text { Katılımcilar } \\
\text { (yaş- } \\
\text { cinsiyet) }\end{array}$ & 997,362 & 3 & 332,454 & 156,613 & ,000 \\
\hline $\begin{array}{l}\text { Vücut } \\
\text { açıları* } \\
\text { sürüş } \\
\text { koşulları }\end{array}$ & 11263,478 & 39 & 288,807 & 136,052 & ,000 \\
\hline $\begin{array}{l}\text { Vücut } \\
\text { açlları* } \\
\text { katılımcılar }\end{array}$ & 214,388 & 39 & 5,497 & 2,590 & ,000 \\
\hline $\begin{array}{l}\text { Sürüş } \\
\text { koşulları* } \\
\text { katılımcılar }\end{array}$ & 822,165 & 9 & 91,352 & 43,034 & ,000 \\
\hline $\begin{array}{l}\text { Vücut } \\
\text { açıları* } \\
\text { sürüş } \\
\text { koşulları* } \\
\text { katılımcılar }\end{array}$ & 489,835 & 117 & 4,187 & 1,972 & ,000 \\
\hline Hata & 1426,500 & 672 & 2,123 & & \\
\hline Toplam & 6600300,000 & 896 & & & \\
\hline $\begin{array}{l}\text { Düzeltilmiş } \\
\text { toplam }\end{array}$ & 1940159,460 & 895 & & & \\
\hline
\end{tabular}

Varyans analiz sonuçları incelendiğinde;

- Eklem bölgeleri,

- Sürüş koşulları,

- Katılımcılar (Yaş-Cinsiyet)

Tekli faktörlerin ana etkileri, ikili etkileşim grupları ve üçlü etkileşim grupları $(\mathrm{p}<0.005)$ vücut açllarında etkilidir.

Vücut açılarında etkili olan değişkenlerin aralıklarını ve gruplarının bulunması amacıyla Duncan çoklu aralık testi yapılmıştır. Tablo 5 'de otomotiv kullanımı esnasında oluşan konfor açılarının sağdan 
alınan ölçümleri ile soldan alınan ölçümlerinin farklı gruplarda olduğu gözlemlenmiștir.

\section{Tablo 5. Vücut Açıları ve Homojenlik Grupları}

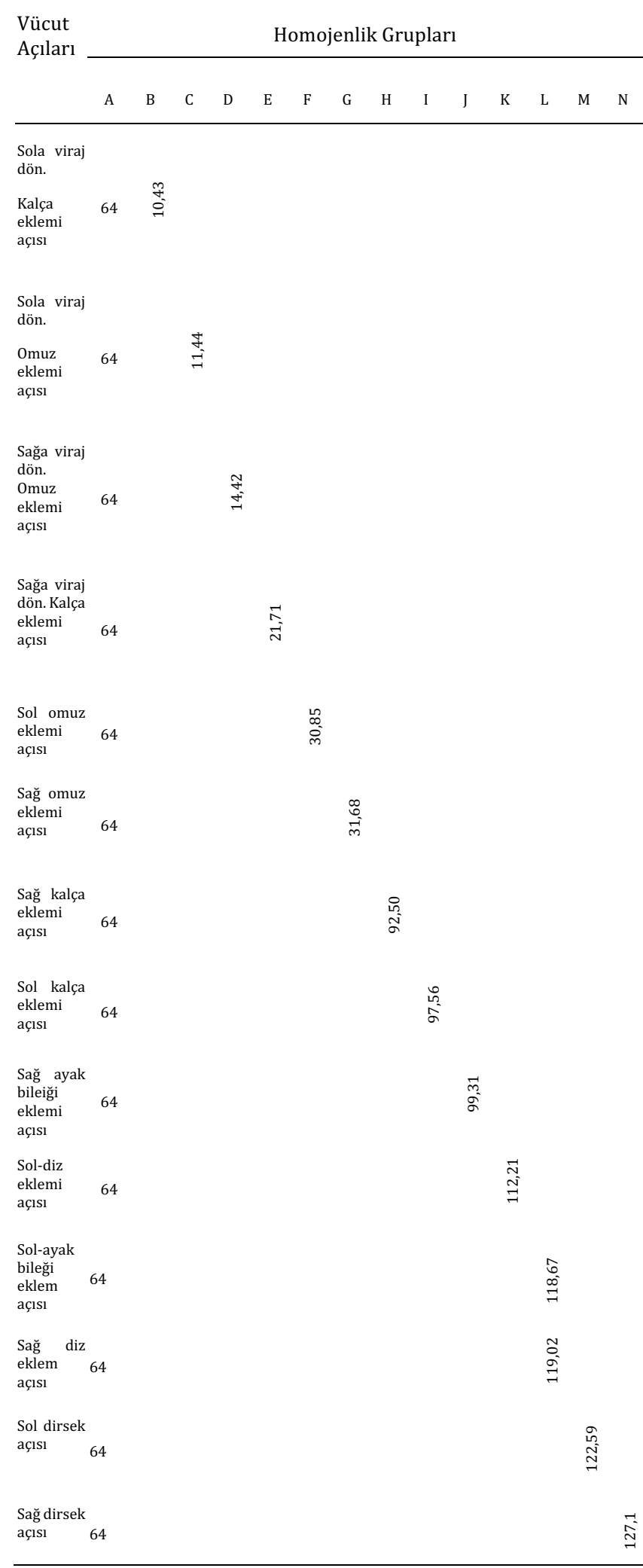

$\mathrm{Bu}$ bulgular, otomotiv kullanımı esnasında sağda vites, multimedya cihazı ve bazı sinyallerin olması, solda ise dikiz aynasının bulunmasinın oturma duruşunu etkilediğini göstermektedir. Ev ortamında herhangi bir koltukta otururken sağ ve sol açlarda bu derece farklılıklar olmamaktadır. Konfor açılarının sayısal değerleri incelendiğinde, en küçük değerin sola viraj dönüşlerinde oluşan kalça eklemi açısı $\left(10,43^{\circ}\right)$ olduğu görülmüştür. En yüksek değerde olan konfor açısı ise sağ dirsek $\left(127,1^{\circ}\right)$ açısıdır.

Tablo 6. Kullanım Şekli ve Homojenlik Grupları

\begin{tabular}{|c|c|c|c|c|c|}
\hline \multirow[b]{2}{*}{ Kullanım Șekli } & \multicolumn{5}{|c|}{ Homojenlik Grupları } \\
\hline & Adet & A & $\mathrm{B}$ & $\mathrm{C}$ & $\mathrm{D}$ \\
\hline $\begin{array}{l}\text { Sağ-viraja } \\
\text { girerek } \\
\text { manevra } \\
\text { yapmak }\end{array}$ & 224 & $70,41^{\circ}$ & & & \\
\hline $\begin{array}{l}\text { 50-km mesafen } \\
\text { kısa-araç } \\
\text { kullanmak }\end{array}$ & 224 & & $71,53^{\circ}$ & & \\
\hline $\begin{array}{l}\text { Sola-viraja } \\
\text { girerek } \\
\text { manevra } \\
\text { yapmak }\end{array}$ & 224 & & & $72,50^{\circ}$ & \\
\hline $\begin{array}{l}\text { 50-km } \\
\text { mesafeden } \\
\text { uzun-araç } \\
\text { kullanmak }\end{array}$ & 224 & & & & $74,02^{\circ}$ \\
\hline
\end{tabular}

Tablo 6'da dört farklı sürüş kullanım formunda oluşan vücut açları incelenmiştir. Duncan analizine göre sağ yönde viraja girmek ile sol yönde viraja girmek arasında istatistiksel olarak farklılık bulunmaktadır. Uzun mesafeli araç kullanımı ile kısa mesafeli araç kullanımı arasında ise istatiksel olarak fark olduğu gözlemlenmiştir.

Tablo 7. Katılımcılar ve Homojenlik Grupları

\begin{tabular}{cccccc} 
& \multicolumn{5}{c}{ Homojenlik Grupları } \\
\cline { 2 - 6 } Yaș & Adet & A & B & C & D \\
\hline Kadın $<45$ yaș & 224 & $70,38^{\circ}$ & & \\
Kadın $>45$ yaș & 224 & & $72,23^{\circ}$ & \\
Erkek $<45$ yaș & 224 & & & $72,66^{\circ}$ & \\
Erkek $>45$ yaș & 224 & & & & $73,19^{\circ}$ \\
\hline
\end{tabular}

Tablo 7'de 45 yaș altı kadın kullanıcıların vücut açıları ile 45 yaş üzeri kadın kullanıcıların vücut açları arasında fark olduğu, aynı şekilde 45 yaş altı ile 45 yaş üzeri erkek kullanıcılar arasında da fark olduğu gözlemlenmiștir. Yaş ile sürüş esnasında oluşan konfor açıları arasında farklılık olduğu görülmüștür. 
Tablo 8. Konfor Açılarının DIN, REBIFE ve RAMSIS ile karşılaștırılması

\begin{tabular}{|c|c|c|c|c|c|c|}
\hline & & $\begin{array}{l}\text { Konfor } \\
\text { Açılarının } \\
\text { Ortalaması }\end{array}$ & $\begin{array}{l}\text { Standart } \\
\text { Sapma }\end{array}$ & DIN & Rebiffe & RAMSIS \\
\hline $\begin{array}{l}\text { Ayak } \\
\text { Bileği, }\end{array}$ & 年0 & $99,31^{\circ}$ & 0,816497 & $90^{\circ}$ & $90^{\circ}$ & $103^{\circ}$ \\
\hline Diz & 吕 & $119,06^{\circ}$ & 12,11318 & $125^{\circ}$ & $95^{\circ}$ & $119^{\circ}$ \\
\hline Kalça & 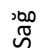 & $97,56^{\circ}$ & 3,68273 & $95^{\circ}$ & $95^{\circ}$ & $99^{\circ}$ \\
\hline Omuz & 吕 & $31,69^{\circ}$ & 1,47196 & $38^{\circ}$ & $10^{\circ}$ & $22^{\circ}$ \\
\hline Dirsek & 梁 & $127,17^{\circ}$ & 1,707825 & $120^{\circ}$ & $80^{\circ}$ & $127^{\circ}$ \\
\hline $\begin{array}{l}\text { Ayak } \\
\text { Bileği }\end{array}$ & $\bar{n}$ & $118,67^{\circ}$ & 11,2574 & $90^{\circ}$ & $110^{\circ}$ & $103^{\circ}$ \\
\hline Diz & $\bar{o}$ & $112,22^{\circ}$ & 5,822013 & $125^{\circ}$ & $135^{\circ}$ & $119^{\circ}$ \\
\hline Kalça & $\bar{n}$ & $92,5^{\circ}$ & 3,937004 & $95^{\circ}$ & $120^{\circ}$ & $99^{\circ}$ \\
\hline Omuz & $\bar{i}$ & $30,86^{\circ}$ & 1,414214 & $38^{\circ}$ & $45^{\circ}$ & $22^{\circ}$ \\
\hline Dirsek & $\bar{n}$ & $122,59^{\circ}$ & 2,286737 & $120^{\circ}$ & $120^{\circ}$ & $127^{\circ}$ \\
\hline $\begin{array}{l}\text { Omuz } \\
\text { Viraj-1 }\end{array}$ & 梁o & $14,42^{\circ}$ & 0,645497 & $* * *$ & $20^{\circ}$ & $15^{\circ}$ \\
\hline $\begin{array}{l}\text { Omuz } \\
\text { Viraj-2 }\end{array}$ & $\bar{i}$ & $11,44^{\circ}$ & 0,645497 & $* * *$ & $30^{\circ}$ & $12^{\circ}$ \\
\hline $\begin{array}{l}\text { Kalça } \\
\text { Viraj-1 }\end{array}$ & $\begin{array}{l}j^{200} \\
\widetilde{N}\end{array}$ & $21,72^{\circ}$ & 2,25 & $* * *$ & $9^{\circ}$ & $24^{\circ}$ \\
\hline $\begin{array}{l}\text { Kalça } \\
\text { Viraj-2 }\end{array}$ & $\overline{0}$ & $10,44^{\circ}$ & 0,866025 & & $11^{\circ}$ & $11^{\circ}$ \\
\hline
\end{tabular}

Tablo 8'de sürüş konforunu etkileyen 14 farklı vücut açısı incelenmiş, ölçümler sonucunda elde edilen verilerin RAMSIS ve DIN standartlarına yakın değerler taşıldığı tespit edilmiştir. Otomotiv iç mekan tasarımında koltuk tasarımı önemli yere sahiptir. Veriler incelendiğinde Kadın kullanıcıların daha dar açılarda otomotiv kullandı̆̆ı, erkek kullanıcıların daha geniş açlarda otomotiv kullandıkları tespit edilmiştir. Bu durum kadın ve erkek fizyolojisinin farklı olmasıyla ilișkili olarak açıklanabilir. 50km'den daha az mesafede araç kullanımında daha geniş açı hesaplanırken, sağa keskin dönüş yapılması durumunda açlların ortalamasının daraldığı tespit edilmiştir. Eklem açıları incelendiğinde sola viraj dönüşündeki kalça eklem açısı $\left(10,43^{\circ}\right)$ en düşük değere sahipken, en geniş eklem açısının ise sağ dirsek açısı $\left(127,17^{\circ}\right)$ olduğu gözlemlenmiştir.

\section{Sonuçlar}

Hayatımızın önemli bir parçası olan otomotivlerde her geçen gün daha fazla vakit geçirmekteyiz. Büyük şehirlerde sıkışık trafikte dur kalk yaparak bir noktadan bir noktaya ulaşmak bazen saatler sürmekte, bu durum, yanlış vücut duruşları yüzünden otomotiv kullanıcılarının kas ve iskelet sistemlerinde oluşan risk altına sokmaktadır. Pek çok bilim adamı otomotiv iç mekanı ve konforu hakkında araştırma yapmış sonuç olarak eklemlerde oluşan konfor açılarının belirli sınırlar çerçevesinde olması gerektiğini belirtmişlerdir.

Otomotiv ergonomisi için yapılan çalışmaları üç farklı temel alanda görmekteyiz. Bu üç farklı temel alanın içinde otomotiv ergonomisi için hazırlanmış yazılımlar, REBA ve RULA analizleri ve görüntüleme teknolojisidir. Bizim çalışmamızda, laboratuvar ortamında otomotiv koltuğu, direksiyon ve pedal takımları 1/1 ölçekli otomotiv modeli kullanılmış, cinsiyet ve yaş farkına bağlı değişebilen konfor açıları incelenmiş. Kadın ve erkek sürücüler arasında sürüş konforu açısından büyük ölçüde fark olduğu gözlemlenmiştir. Kadınların erkeklerden daha dar açılar ile araç kullandığı, uzun mesafe sürüşlerde konfor açılarının genişlediği kısa mesafede daraldığı gözlemlenmiştir. Otomotiv kullanıcıları için ilerleyen senelerde firmaların uzun yol ve şehir içi kullanımı için koltuk, direksiyon ve pedallarda, farklı ölçüler ve sertlikler sunması önerilmektedir. Gelecek çalıșmalarda, farklı araç sınıfları içinden uygun koltuk modelinin araştırılması planlanmaktadır.

\section{Tartışma}

Günlük otomotiv kullanımında, kas ve iskelet sistemimizin risk altında olup olmadığını anlamak için yapılmış olan bu çalışmada cinsiyet ve yaş farklarına göre konfor açıları incelenmiştir. Otomotiv kullanıcılarının konfor açlları 1945'lerden sonra merak konusu olmuş hem otomotiv imalatı yapan firmalar hem de bilim adamları konuyu detaylı olarak araştırmışlar, hatta otomotiv kullanımını daha rahat ve fonksiyonel hale getirmek için yeni buluşlara imza atmışlardır. Eldem ve arkadaşları (2019) yapmış oldukları çalışmada, otomotiv kullanıcılarında CATIA V5 programı kullanarak insan otomotiv modellemesi yapmışlar, REBA ve RULA analiz yöntemleri kullanarak otomobil sürücülerinde kas iskelet sisteminde oluşan risk analizlerini yapmışlardır. Yapılan ergonomik değerlendirmelere göre; sürücü koltuğu ve gaz pedalı arasındaki mesafelerin yeniden tasarlanması, sürücü koltuklarının sırt eğimlerinin düzenlemesi ve 
sol ayak için özel bir ayak koyma yeri planlanması şeklinde olmuştur. Naddeo ve Memoli (2009) yapmış oldukları çalışmada FIAT otomotiv firmasının geliştirmiş olduğu "Manikin" yazılımını kullanarak dijital insan modelleri oluşturmuşlar oluşturdukları modellere REBA analizi yapmışlardır, "Manikin' yazılımı ile elde edilen konfor açılarının en sağlıklı çözüm olduğunu iddia etmişlerdir. Yapılan çalışmalar incelendiğinde iki boyutlu veya üç boyutlu modellerin farklı sonuçlar verdiği, ülkeden ülkeye farklı sonuçlar alındığı hatta koltuktan koltuğu bile farklı konfor açların oluştuğu gözlemlenmiștir.

\section{Teşekkür}

Çalışmamızın görüntüleme yöntemi analizi kısmının yapılması aşamasında, Oklahoma State Universitesi OSU- Mixed Reality Laboratuvarını kullanma imkanı sundukları için İnsan Bilimleri Fakültesi yönetimine teşekkür ederiz.

\section{Çıkar Çatışması}

Yazarlar tarafından herhangi bir çıkar çatışması beyan edilmemiştir.

\section{Kaynaklar}

Andreoni, G., Rabuffetti, M., Pedotti, A., Quattrocolo, S., Cerrone, M., \& Tarzia, A. (1999). Accessibility Simulation and Ergonomic Evaluation for Virtual Prototyping (No. 1999-01-1925). SAE Technical Paper.

Carayon, P., Smith, M. J. (2000). Work organization and ergonomics. Applied ergonomics, 31(6), 649662 .

Chaffin, D.B. \& Andersson. G.B., (1991). Occupational Biomechanics. $2^{\text {nd }}$ ed. Wiley, New York, USA.

DIN 33408-1:2008-03, Körperumrissschablonen Teil 1: Für Sitzplätze

Eldem, C., Neslihan, T. O. P., Şahin, H. (2019). Dijital insan modelleri kullanarak otomobil sürücüsü duruş pozisyonlarının ergonomik değerlendirilmesi üzerine bir çalıșma. Gazi Mühendislik Bilimleri Dergisi (GMBD), 5(1), 22-31.

Graf, M., Guggenbühl, U., Krueger, H. (1995). An assessment of seated activity and postures at five workplaces. International Journal of Industrial Ergonomics, 15(2), 81-90.
Grieco, A. (1998). Application of the concise exposure index (OCRA) to tasks involving repetitive movements of the upper limbs in a variety of manufacturing industries: preliminary validations. Ergonomics, 41(9), 1347-1356.

Gowtham, S., Ramnaath, M., Sudharsan, S., Kumar, B. L., Praneeth, V., Dinesh, S., Subramaniyam, M. (2020, August). Seating comfort analysis: a virtual ergonomics study of bus drivers in private transportation. 3rd International Conference on Advances in Mechanical Engineering (ICAME 2020) (Vol. 912, No. 2, p. 022018). IOP Publishing. doi:10.1088/1757-899X/912/2/022018

Guenaelle, P. (1995, March). One methodology to evaluate automotive seat comfort. In Proceedings of the Third International Conference on Vehicle Comfort and Ergonomics, Bologna, Italy (pp. 2931).

Gyi, D. E., Porter, J. M., Robertson, N. K. (1998). Seat pressure measurement technologies: considerations for their evaluation. Applied Ergonomics, 29(2), 85-91.

Huang, Y. H., Robertson, M. M. Chang, K. I., (2004). The role of environmental control on environmental satisfaction, communication, and psychological stress: effects of office ergonomics training. Environment and Behavior, 36(5), 617637.

Kamp, I. (2012). The influence of car-seat design on its character experience. Applied ergonomics, 43(2), 329-335.

Kaya, Ö., Akalp, G. (2017). İş sağlığı ve güvenliği açısından elle taşıma işlerinin değerlendirilmesi (tekstil ve otomotiv sektörü örneği). Is, Güc: Endüstri Iliskileri ve Insan Kaynaklari Dergisi, 19(2), 79-90.

Kaya, Ö., Özok, A. F. (2017). Tasarımda antropometrinin önemi. Mühendislik Bilimleri ve Tasarım Dergisi, 5, 309-316.

Kuebler, T., Wirsching, H., Barnes, D. (2018). RamsisDigital Human Modeling for Optimized Safety and Survivability of the Warfighter.

Latko, W. A., Armstrong, T. J., Franzblau, A., Ulin, S. S., Werner, R. A. Albers, J. W., (1999). CrossSectional Study of The Relationship Between 
Repetitive Work and The Prevalence of Upper Limb Musculoskeletal Disorders. American Journal of İndustrial Medicine, 36(2), 248-259.

Lay, W. E., \& Fisher, L. C. (1940). Riding comfort and cushions (No. 400171). SAE Technical Paper.

Mah, C.D., Hulliger, M., Lee, R.G. O'Callaghan, I., (1994). Quantitative Analysis Of Human Movement Synergies: Constructive Pattern Analysis for Gait. Journal of Motor Behavior, 26, 83-102.

Naddeo, A., Cappetti, N., Vallone, M., Califano, R. (2014). New trend line of research about comfort evaluation: proposal of a framework for weighing and evaluating contributes coming from cognitive, postural and physiologic comfort perceptions. In Advances in Social and Organizational Factors, Edited by Peter Vink, Published By "Advances in Human Factors and Ergonomics" Conference.

Park, W., Martin, B. J., Choe, S., Chaffin, D. B. Reed, M. P. (2005). Representing and Identifying Alternative Movement Techniques for GoalDirected Manual Tasks. Journal of Biomechanics, 38(3), 519-527.

Schmidt, S., Amereller, M., Franz, M., Kaiser, R., Schwirtz, A. (2014). A literature review on optimum and preferred joint angles in automotive sitting posture. Applied ergonomics, 45(2), 247-260.

Seidl, A. (1997). RAMSIS-A new CAD-tool for ergonomic analysis of vehicles developed for the German automotive industry (No. 970088). SAE Technical Paper.

Straker, L. \& Mekhora, K. (2000). An Evaluation of Visual Display Unit Placement by Electromyography, Posture, Discomfort and Preference. International Journal of Industrial Ergonomics, 26(3), 389-398.

Ulker O. (2020). Koltuk İmalatındaki Zorlanmaların BAUA Yöntemi ile Değerlendirilmesi, Ergonomi, $3(1), 45-54$.

Vogt, C., Mergl, C., Bubb, H. (2005). Interior layout design of passenger vehicles with RAMSIS. Human Factors and Ergonomics in
Manufacturing \& Service Industries, 15(2), 197212.

Zhang, X., \& Chaffin, D. B. (1996, October). Task effects on three-dimensional dynamic postures during seated reaching movements: an analysis method and illustration. In Proceedings of the Human Factors and Ergonomics Society Annual Meeting (Vol. 40, No. 13, pp. 594-598). Sage CA: Los Angeles, CA: SAGE Publications.

Zhang, X., Nussbaum, M. A. Chaffin, D. B. (2000). Back Lift Versus Leg Lift: an Index and Visualization of Dynamic Lifting Strategies. Journal of Biomechanics, 33(6), 777-782.

Zhou, B., Chen, L., Tian, J., Peng, Z. (2017, June). Learning-based seat belt detection in image using salient gradient. In 2017 12th IEEE Conference on Industrial Electronics and Applications (ICIEA) (pp. 547-550). IEEE. 